\title{
Modeling the Mechanical Properties of Clay Powder Filled Recycled Low Density Polyethylene Composites
}

\author{
Gerald Okwuchi Onyedika1*, Genevive Chinyere Onuegbu², Chukwudike Onuoha ${ }^{3}$ \\ ${ }^{1}$ Department of Chemistry, Federal University of Technology, Owerri, Nigeria \\ ${ }^{2}$ Department of Polymer and Textile Engineering, Federal University of Technology, Owerri, Nigeria \\ ${ }^{3}$ Department of Materials and Metallurgical Engineering, Federal University of Technology, Owerri, Nigeria \\ Email: ^gonyedik@mtu.edu, genevive.onuegbu@futo.edu.ng, chukwudike.onuoha@futo.edu.ng
}

How to cite this paper: Onyedika, G.O., Onuegbu, G.C. and Onuoha, C. (2020) Modeling the Mechanical Properties of Clay Powder Filled Recycled Low Density Polyethylene Composites. Journal of Materials Science and Chemical Engineering, 8, 36-47.

https://doi.org/10.4236/msce.2020.87004

Received: December 24, 2019

Accepted: July 28, 2020

Published: July 31, 2020

Copyright $\odot 2020$ by author(s) and Scientific Research Publishing Inc. This work is licensed under the Creative Commons Attribution International License (CC BY 4.0).

http://creativecommons.org/licenses/by/4.0/

\section{(c) (i) Open Access}

\begin{abstract}
This study modeled some mechanical properties of clay powder filled recycled low-density polyethylene, rLDPE (rLDPE composite). The rLDPE is commonly referred to as used sachet water bags. The clay powder (filler) was obtained by sun-drying, grinding, and sieving. Two particle sizes of clay powder were used: $-90 \mu \mathrm{m}$ and $-425 \mu \mathrm{m}$ to represent the passing sizes at different clay powder contents of 5, 10, 15 and $20 \mathrm{wt} \%$ which were thoroughly mixed with the recycled low-density polyethylene in an injection molding machine at $173^{\circ} \mathrm{C}$. The results showed that the tensile strength, tensile modulus, hardness, flexural strength, fatigue strength and hardness increased with increase in clay powder contents. However, there were decreases in strain-at-breakage and shear strength as clay powder content increased. Model equations showed that smaller particle size enhanced the mechanical properties and equations generated can be used to predict the properties of composites at predetermined clay contents. Standard deviations obtained for the various mechanical properties show that the model, in most cases had the lowest degree of scatter (dispersion) than those of $-90 \mu \mathrm{m}$ and $-425 \mu \mathrm{m}$. Hence, these models are suitable to predict outcomes of the properties of the clay filled recycled low-density polyethylene composites.
\end{abstract}

\section{Keywords}

Clay, Composite, Modeling, Particle Size, Properties, rLDPE

\section{Introduction}

Recently, many researchers have developed interest in polymer composite as a 
way to recreate new products. Several contributing factors such as high strength-to-weight ratio, inability to conduct electricity, corrosion resistance, high rate of load transfer and its economical process have led to the application of polymer composites in many fields such as engineering, aerospace, medical, automotive, agriculture, information and communication, domestic components and so on [1] [2].

Polymer composites consist of the primary phase known as the matrix phase and the secondary phase referred to as the reinforcement. The matrix is ductile and it binds the reinforcing agent in a composite while the reinforcing agent is strong and it enhances the mechanical properties of the polymer composite. The composite that is well formulated possesses a better property than the individual component [2]. The most popularly used thermoplastic is polyethylene (PE) because it is tough, chemically inert, unable to absorb moisture, exhibits low coefficient of friction, easy to process, unable to conduct electricity. Polyethylene is used in making pipes, containers and other products. The composite of polyethylene is widely used in many fields due to its improvement in mechanical and physical properties unlike the pure polyethylene. Polyethylene composites are used in packaging, electrical component, storage of thermal energy, automotive, biomedical and aerospace [3].

Clay which is made up of inorganic and organic materials can be found locally within the environment and has been applied in the production of various composites. It has been classified as being a very good and distinct organic reinforcing filler. The use of clay as a reinforcing agent in the production of composite products has a good reinforcing effect over the polymer matrix as a result of its inherent properties such as layered structure, high stiffness about 150 - $250 \mathrm{GPa}$, high strength and surface area about $700-800 \mathrm{~m}^{2}$. Physicochemical conditions, processing method and high surface area of clay, are the factors that can lead to increase in interfacial interactions between the polymer and the reinforcing phases. Clay powder can improve the mechanical properties of composites more than the composites prepared from mineral/inorganic fillers such as glass fiber, talc, metal oxides and others [4].

Many researchers have used clay in the filling polymers, for instance Longanathan et al., (2011) used nanofibers and montmorillonite based organo-clay to fill polypropylene by melt-spinning and it was observed that their structures and mechanical properties were enhanced [5] [6]. It was observed that mechanical properties and free vibration characteristics were improved. Different weight percentages of fibers, $5 \%, 10 \%, 20 \%, 25 \%$, and $30 \%$ were also used to fill the composites. The results showed that $5 \%$ addition of nano clay and $15 \%$ jute fibers yielded the best tensile strength, impact strength and vibration behavior of the composites whereas $5 \%$ nano clay and $25 \%$ jute produced composite with best flexural strength. Increase of nano clay or jute beyond these values reduced the respective properties.

In recent years, the application of nano clay in bio-degradable polymers also 
attracts more and more interest, which aims to enhance the tensile modulus, tensile strength and the interfacial interaction of bio-resin [7]. Better properties of nanocomposites are believed to be achieved even at a small amount of clays when clays are fully exfoliated [8] [9] [10] [11]. Different models have been used to predict various characteristics and mechanical properties of composites. The models predicted results which conformed with the experimental results [12] [13] [14].

Recently, the clay powder filled recycled low density polyethylene composites were prepared using filler loadings of $0 \%, 5 \%, 10 \%, 15 \%$ and $20 \%$ with particle sizes of $90 \mu \mathrm{m}$ and $425 \mu \mathrm{m}$ passing sizes. The result showed improved mechanical properties [15]. In this work, the model predicted the effects of clay powder and particle sizes on some mechanical properties of recycled low-density polyethylene (rLDPE) composites that were determined in [15].

\section{Materials and Methods}

The clay used was obtained from Awo-Omamma village in Imo state, Nigeria. The recycled low density polyethylene used was picked from Federal University of Technology, Owerri, Imo State, Nigeria. rLDPE were sorted, washed, sun-dried and ground to powder form.

\subsection{Composites Preparation}

The clay (filler) was sun-dried, ground to fine particles and sieved into two mesh size ranges, namely: $-90 \mu \mathrm{m}$ (particles passing through $90 \mu \mathrm{m}$ sieve down to submicron or nanoparticles) and -425 to $+90 \mu \mathrm{m}$ (particles passing through 425 $\mu \mathrm{m}$ sieve but retained on $90 \mu \mathrm{m}$ sieve) respectively. For the sake of simplicity, these size ranges are subsequently referred to as 90 and $420 \mu \mathrm{m}$ respectively. That is, $90 \mu \mathrm{m}$ filler particles are the undersize of $90 \mu \mathrm{m}$ sieve while $425 \mu \mathrm{m}$ particles are the oversize of $90 \mu \mathrm{m}$ sieve plus the undersize of $425 \mu \mathrm{m}$ sieve. In other words, all the oversize of $425 \mu \mathrm{m}$ sieve were rejected while the undersize were used as filler in polypropylene matrix. Different clay powder contents; 5, 10, 15, and $20 \mathrm{wt} \%$ were homogenously mixed with recycled low-density polyethylene at the two particle sizes studied.

\subsection{Determination of Mechanical Properties}

\subsubsection{Tensile Properties}

In the determination of tensile properties of the prepared rLDPE composites, the injection molded sheet was cut into dumb bell shape of specimen dimensions $160 \mathrm{~mm} \times 20 \mathrm{~mm} \times 3 \mathrm{~mm}$ and placed on Universal Testing machine at a head speed of $5 \mathrm{~mm} / \mathrm{min}$ according to ASTM standard. The tensile strength, tensile modulus and strain-at-breakage of the composites were calculated using Equations (1)-(3).

$$
\text { Tensile Strength }(\mathrm{MPa})=\frac{p}{h b}
$$

where: $p=$ Pulling force $(\mathrm{N})$ 
$b=$ Width of specimen $(\mathrm{mm})$

$h=$ Thickness of specimen $(\mathrm{mm})$

\subsubsection{Strain-at-Breakage}

The strain-at-breakage was determined using Equation (2)

$$
\text { Strain-at-Breakage }=\frac{L_{f}-L_{i}}{L_{i}} \times 100
$$

where, $L_{i}=$ initial length of specimen

$L_{f}=$ final length of specimen

\subsubsection{Tensile Modulus}

The tensile modulus of the composites were calculated using the formula in 3

$$
\text { Tensile Modulus }(\mathrm{MPa})=\frac{\sigma}{\varepsilon}
$$

$$
\begin{aligned}
& \sigma=\text { Stress }\left(\mathrm{N} / \mathrm{m}^{2}\right) \\
& \mathcal{E}=\text { Strain }
\end{aligned}
$$

\subsubsection{Flexural Strength}

For the flexural strength the specimen was cut to $300.0 \mathrm{~mm}$ length, $19 \mathrm{~mm}$ breadth and $3.3 \mathrm{~mm}$ thick. It was performed according to ASTM. D790 using Universal Testing Machine at a constant rate of $2 \mathrm{~mm} / \mathrm{min}$. Test specimen was cut to $300 \mathrm{~mm}$ length, $19 \mathrm{~mm}$ breadth and $3.3 \mathrm{~mm}$ thick.

The flexural strength was calculated using Equation (4)

$$
F_{T}=\frac{3 P L}{b d^{2}}
$$

where: $F_{T}=$ flexural strength

$$
\begin{aligned}
& P=\text { Max flexural force }(\mathrm{N}) \\
& L=\text { Span length of the material }(\mathrm{m}) \\
& b=\text { Breadth of material }(\mathrm{m}) \\
& d=\text { Thickness of material }(\mathrm{m})
\end{aligned}
$$

\subsubsection{Shear Strength}

In the determination of shear strength, the specimen was inserted into the shear test box, a continuous steady load was added till it pierced through the specimen. The force used for piercing the sample was measured (shearing force). The shear strength is given in Equation (5).

Shear Strength $=$ shear force/cross sectional area of spindle

where spindle needle area $(A)=\frac{\pi d^{2}}{4}$ (for $\left.d=6 \mathrm{~mm}\right)$.

\subsubsection{Fatigue Strength}

Fatigue strength was tested by determining the number of cycles needed to crack the material when stress was applied below its tensile strength $\left(n_{i}\right)$ and the number of cycles needed to enlarge the crack to a yield point before failure occurred, 
$\left(n_{p}\right)$, as given in Equation (6).

$$
\text { Fatigue } \operatorname{Life}\left(N_{F}\right)=n_{i}+n_{p} \text { measured in cycles }
$$

\subsubsection{Hardness Test (Brinnel Hardness)}

Hardness test was carried out using a tensiometer UTM (Model No.8889 made in England by Tensiometer Ltd.). A steel ball of diameter of $10 \mathrm{~mm}$ was forced into the material under a load, $F$. After removal of the load, the two diagonals $X$ and $Y$ of the indentation left on the surface of each sample was measured and the arithmetic mean (d) was calculated. The Brinnel hardness was computed using the relationship in Equation (7)

$$
\mathrm{HBN}=\frac{2 P}{\pi D\left(D-\sqrt{D^{2}-d^{2}}\right)}
$$

where: $P=$ constant axial load

$D=$ Brinnel bulb diameter indenter

$d=$ Depth of indentation (to be measured from the test)

$\mathrm{HBN}=$ Brinnel Hardness Number $(\mathrm{N} / \mathrm{mm})$

\subsection{Modeling}

Experimental results were modeled using MatLab 2009 Version. This was done by generating the model equations of each particle size and examining the goodness of fit to determine the model that best fits the property. The following goodness of fits was examined and compared to choose the best model for each property investigated; Coefficient of Regression $\left(R^{2}\right)$ : value closer to 1 is more useful for prediction while value closer to 0 is more useful for prediction for Sum of Squares Due to Error (SSE) and Root Mean Squared Error (RMSE).

The modeling was based on comparison between equations for $90 \mu \mathrm{m}$ and 425 $\mu \mathrm{m}$ passing sizes and choosing the one that has $\mathrm{R}^{2}$ nearer to 1 because it is more useful for prediction. With these respective model equations, the properties can be predicted for clay powder contents that were not experimented on. The model curves were observed to align closely with the curve of the particle size that gave the model equations. The model curves were plotted alongside with experimental curves for the purpose of comparison.

\section{Results and Discussion}

\subsection{Tensile Strength}

Figure 1 shows the effect of clay powder contents on the modeled and unmodeled tensile strength of recycled low-density polyethylene composites at $90 \mu \mathrm{m}$ and $425 \mu \mathrm{m}$ passing particle sizes respectively. From Figure 1, the modeled and unmodeled tensile strength of recycled low-density polyethylene composites increased alongside with clay powder content at the two particle sizes studied, these were due to the high strength of the clay. Figure 1 also shows that $90 \mu \mathrm{m}$ passing particle size yielded higher tensile strength (For both modeled and 


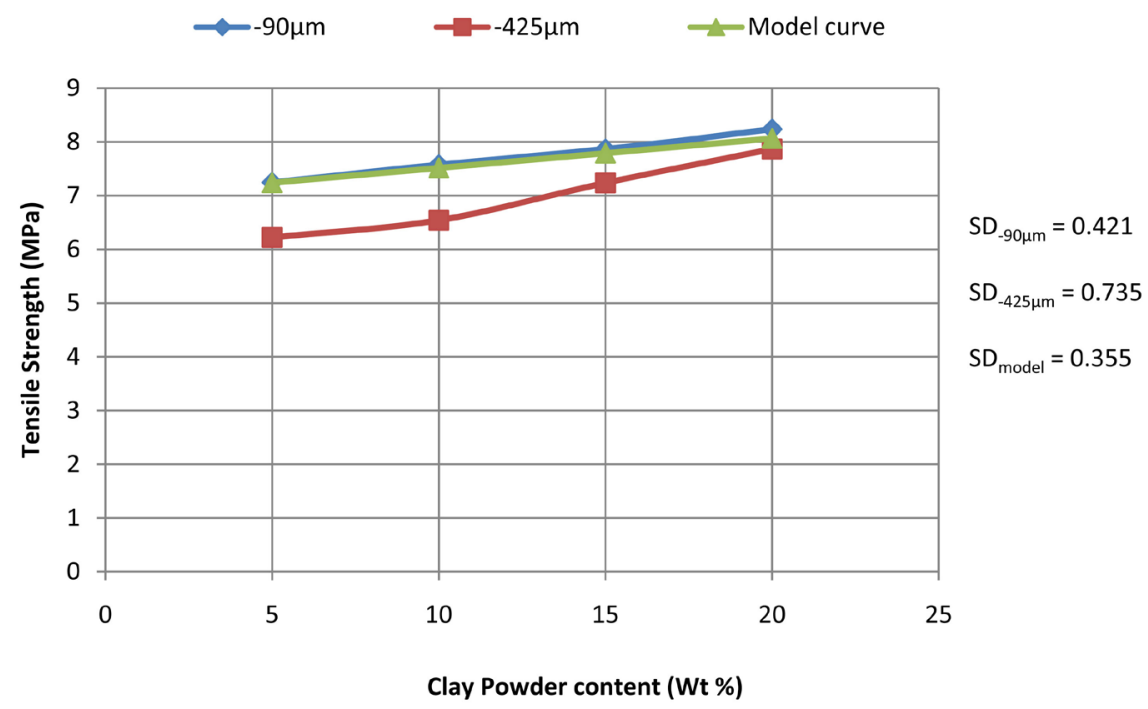

Figure 1. Variation of the tensile strength with clay powder content for model and unmodelled curves for the rLDPE composites at $-90 \mu \mathrm{m}$ and $-425 \mu \mathrm{m}$.

unmodeled tensile strength), than $425 \mu \mathrm{m}$ particle size. This is as a result of increase in surface area of the $-90 \mu \mathrm{m}$ clay particle size that increased the rate of attraction of clay powder to the recycled low-density polyethylene.

The model equation developed for the prediction of tensile strength is given in Equation (8)

$$
\text { T. } S_{90 \mu \mathrm{m}}=0.055 x+6.963
$$

where T. $S_{90 \mu \mathrm{m}}$ is the tensile strength at $-90 \mu \mathrm{m}$ clay particle size and $x$ is the filler content.

The model curve was found to align closely with the curve of the clay particle size that gave the model curve. From the model equation generated, it was possible to predict the tensile strength of any clay powder content even the values that were not experimented on.

Furthermore, standard deviations for the series of data obtained for each particle size range and the model as indicated in Figure $1\left(\mathrm{SD}_{-90 \mu \mathrm{m}}, \mathrm{SD}_{-425 \mu \mathrm{m}}\right.$ and $\mathrm{SD}_{\text {model }}$ ) show that the model has the lowest value implying that it has the lowest degree of scatter from the mean value. This attests to the fact that the model is best suited for prediction.

\subsection{Strain-at-Breakage}

Figure 2 shows the effect of clay powder contents on the modeled and unmodeled strain-at-breakage of rLDPE composites. It was shown that strain-at-breakage decreased as clay powder content increased. This is as result of inert and hard nature of the clay which decreased the plasticity of the rLDPE thereby decreasing its ductility. This is in agreement with the work of Onuegbu and Madufor [12] who found that the strain-at-breakage decreased with increase in clay powder contents. 


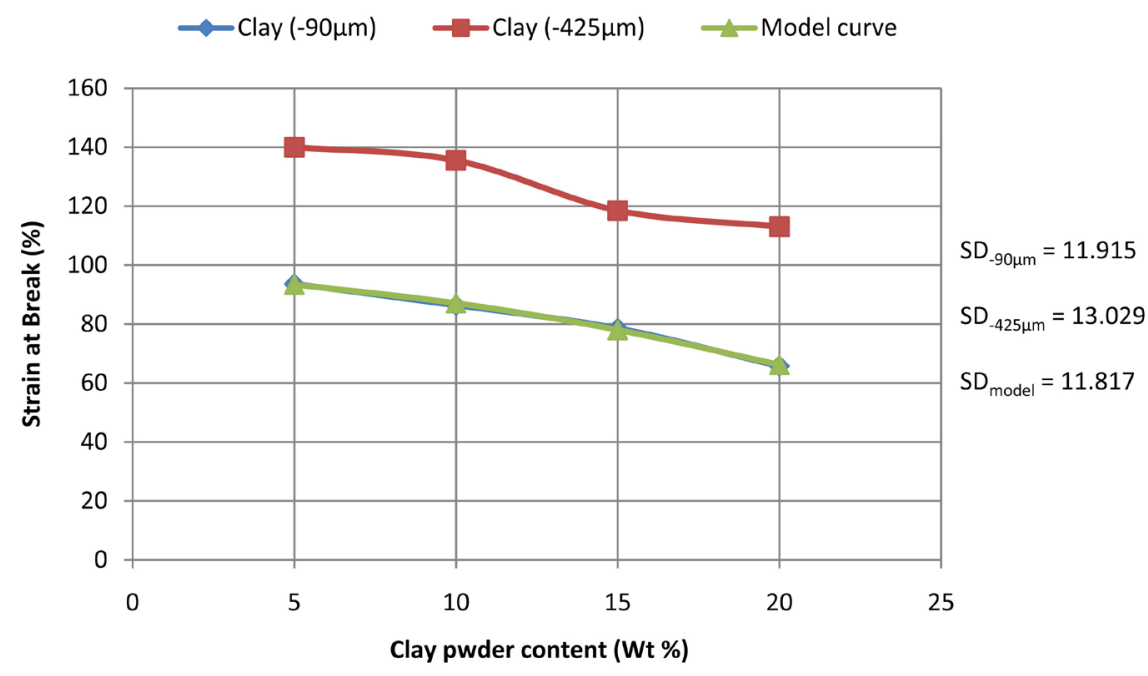

Figure 2. Variation of the strain-at-break with clay powder content for model and unmodelled curves for the rLDPE composites at $-90 \mu \mathrm{m}$ and $-425 \mu \mathrm{m}$.

Model equation for strain-at-breakage is given in Equation (9):

$$
\text { S. } B_{90 \mu \mathrm{m}}=-0.001 x^{2}-1.661 x+138.6
$$

Also, the model shows that it is possible to predict the value of strain-at-breakage for any clay powder content. It also shows that smaller particle sizes yield better results.

The standard deviations as shown in Figure 2 also show that the model has the lowest standard deviation, an indication that its degree of scatter is least, hence suitable for prediction.

\subsection{Tensile Modulus}

The data on the model and un-model modulus of filled rLDPE are illustrated in Figure 3. The figure shows that the model and un-model tensile modulus of the composites increases with increases in clay powder contents which means that incorporation of the clay powder improved the stiffness of the composites.

The model equation for the prediction of tensile modulus is expressed in Equation (10).

$$
\text { T.M } \mathrm{M}_{90 \mu \mathrm{m}}=0.006 x^{2}+0.04 x+127.3
$$

The model equation also shows that smaller particle sizes yield better results. Tensile modulus can also be predicted at any chosen clay powder content with the aid of the model equation generated.

The values of standard deviation obtained for tensile modulus also showed that the model has the least value, meaning that it has the least degree of scatter.

\subsection{Flexural Strength}

Figure 4 shows the flexural strength of rLDPE composites at $90 \mu \mathrm{m}$ and $425 \mu \mathrm{m}$ 


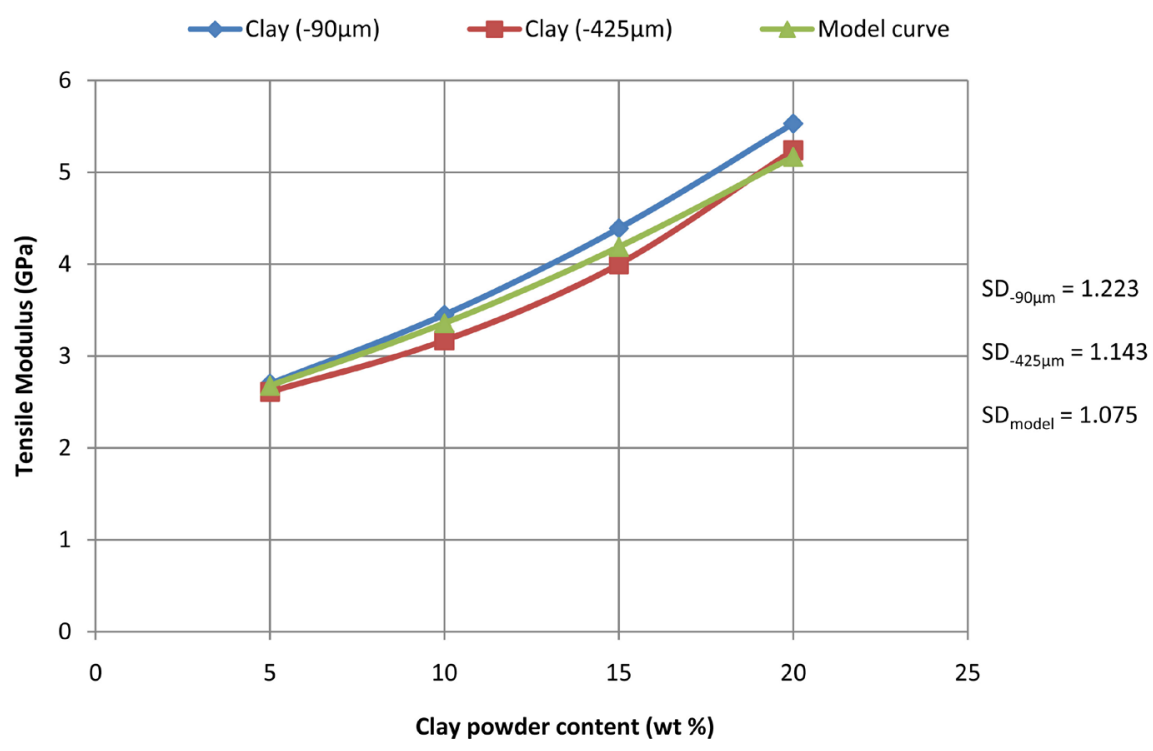

Figure 3. Variation of Tensile Modulus with Clay powder content for model and unmodel curves for the rLDPE composites at $-90 \mu \mathrm{m}$ and $-425 \mu \mathrm{m}$.

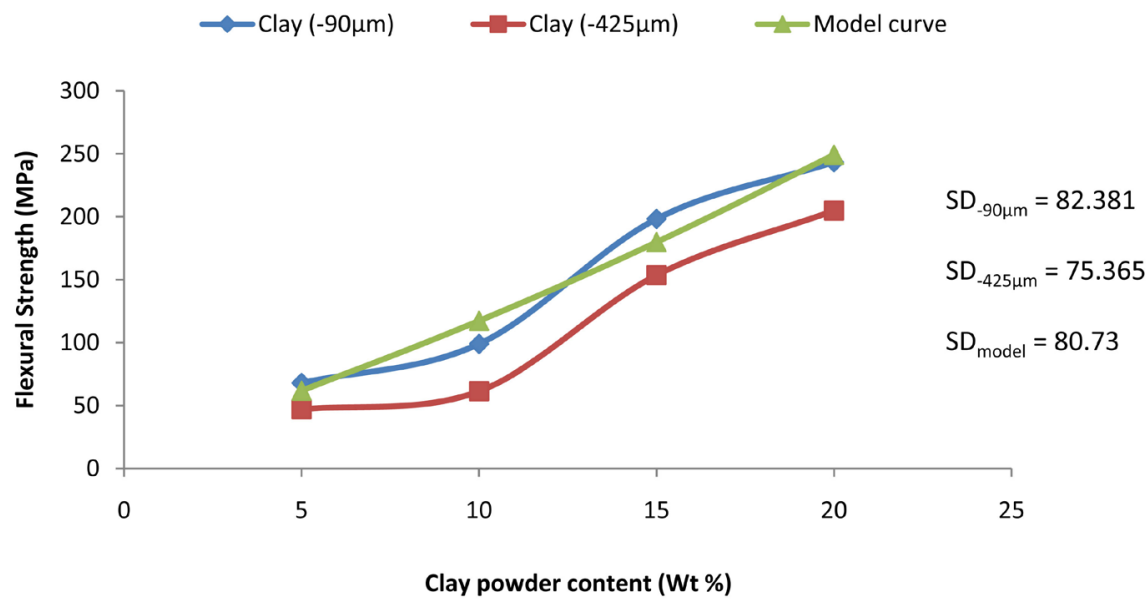

Figure 4. Variation of Flexural Strength with Clay powder content for model and unmodel curves on the rLDPE composite at $-90 \mu \mathrm{m}$ and $-425 \mu \mathrm{m}$.

clay particle sizes. The model and unmodeled flexural strength of the composites were found to increase as more clay powder was added to each particle size due to resistance of bending forces applied.

Model equation generated for the prediction of the flexural strength at any clay powder content is given in Equation (11),

$$
\text { F. } S_{90 \mu \mathrm{m}}=0.14 x^{2}+8.991 x+13.32
$$

which also shows that the smaller the particle size, the better the mechanical property [16].

The standard deviations however show that the model has a value of standard deviation between those of $-90 \mu \mathrm{m}$ and $-425 \mu \mathrm{m}$. This implies that its degree of scatter is a compromise between the two particle size ranges. 


\subsection{Shear Strength}

The shear strength of the rLDPE composites of clay powder at the particle sizes of $90 \mu \mathrm{m}$ and $42 \mu \mathrm{m}$ were observed to decrease with increase in powder contents. Moreover, at $90 \mu \mathrm{m}$, the shear strength was higher than that of $425 \mu \mathrm{m}$ particle size. The reason is that more stress was required to cut across a given area of composites with $90 \mu \mathrm{m}$ clay particle size than with that with $425 \mu \mathrm{m}$ clay particle size.

The model equation for shear strength is given in Equation (12).

$$
\text { S.S. }_{90 \mu \mathrm{m}}=0.008 x^{2}-1.147 x+72.96
$$

This also confirmed that the composite with $90 \mu \mathrm{m}$ clay particle size improved the properties better than the $425 \mu$ m clay particle size. From the model equation generated, values of shear strength can be predicted at any clay powder content.

The least value of standard deviation, as shown in Figure 5, was obtained for $-425 \mu \mathrm{m}$ followed by the model and finally the $-90 \mu \mathrm{m}$. It is obvious from the values that the model has a standard deviation (6.117) very close to that of -425 $\mu \mathrm{m}$ (6.107) meaning that there is a low degree of scatter.

\subsection{Fatigue Strength}

Figure 6 shows that the fatigue strength for clay powder rLDPE composites Model and un-model fatigue increases with increase in clay powder content at both $90 \mu \mathrm{m}$ and $425 \mu \mathrm{m}$ particle sizes considered. This is as a result of the improved stiffness of the material.

Model equation,

$$
\text { F. } S_{90 \mu \mathrm{m}}=0.02 x^{2}+0.22 x+50.5
$$

also confirmed that lower particle size yields better properties. Hence, with the model equation generated, values of fatigue strength can be predicted at any clay powder content.

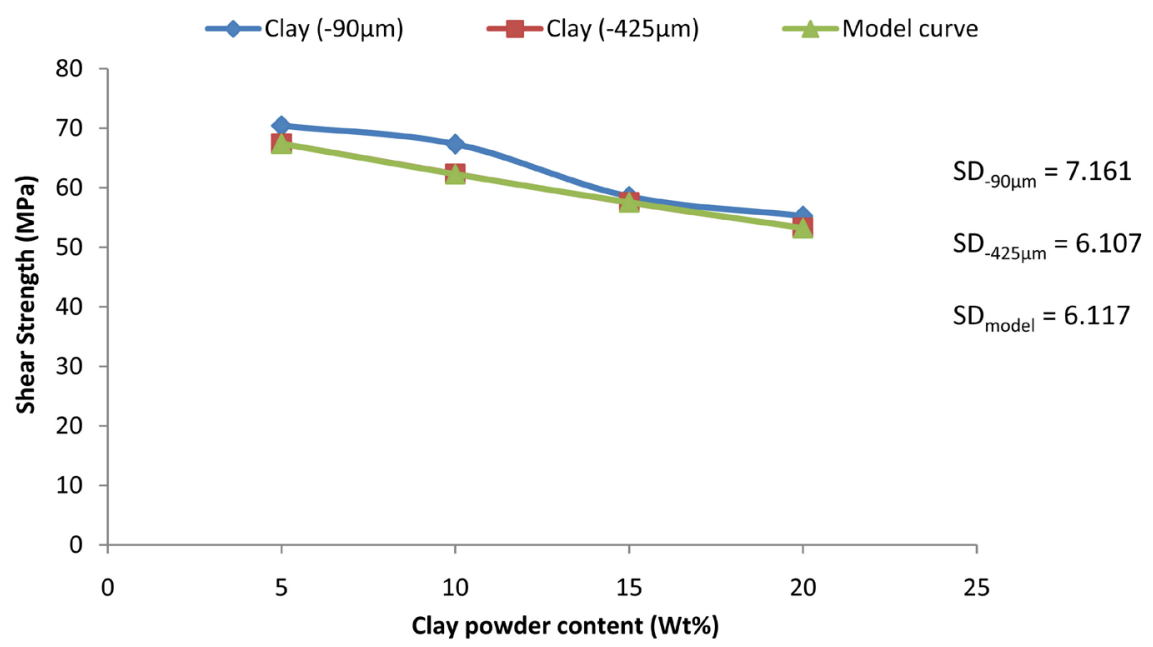

Figure 5. Variation of shear strength with clay powder content for model and unmodel curves at $-90 \mu \mathrm{m}$ and $-425 \mu \mathrm{m}$. 


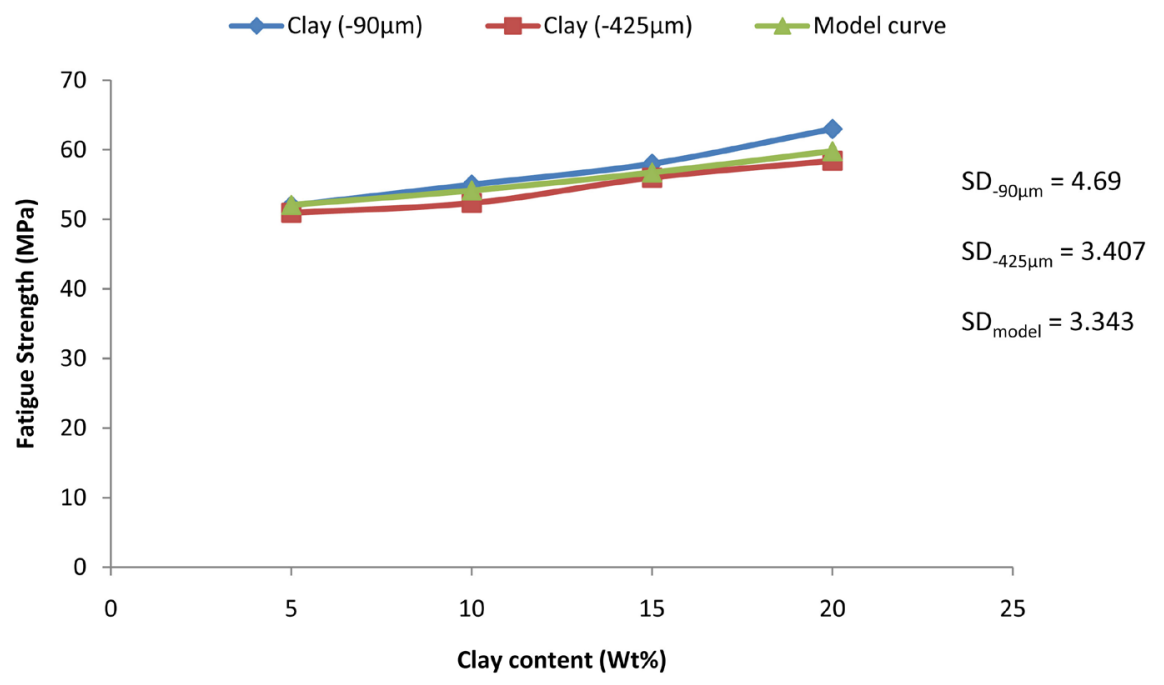

Figure 6. Variation of fatigue strength with clay powder content for model and unmodel curves at $-90 \mu \mathrm{m}$ and $-425 \mu \mathrm{m}$.

The standard deviations as shown in Figure 6 also show that the model has the lowest standard deviation, an indication that its degree of scatter is least, hence suitable for prediction.

\subsection{Hardness (Brinell Hardness)}

The hardness of the rLDPE composite with the $90 \mu \mathrm{m}$ and $425 \mu \mathrm{m}$ clay particle passing sizes were observed to increase with increase in the clay powder content. This is due to enhancements of the abrasion and impact strength by finer particle size of the $90 \mu \mathrm{m}$ clay particle size than the rLDPE composite with $425 \mu \mathrm{m}$ clay particle passing size.

The model equation generated for prediction purposes is given in Equation (14)

$$
\mathrm{H}_{\cdot 90 \mu \mathrm{m}}=0.007 x^{2}+0.261 x+40.54
$$

Hence, with the model equations generated, the values of hardness can be predicted at any clay powder content.

The standard deviations as shown in Figure 7 again show that the model has the lowest standard deviation, an indication that its degree of scatter is least, hence suitable for prediction.

\section{Conclusion}

From the study, the models for the mechanical properties of clay powder filled rLDPE composite at two different clay particle size ranges have been determined. The tensile strength, tensile modulus, flexural strength, fatigue strength and hardness of the clay filled rLDPE were observed to increase with increase in clay powder content for the model and un-model. An improved property was obtained at clay particle passing size of $90 \mu \mathrm{m}$ than at $425 \mu \mathrm{m}$. Strain-at-break and shear strength decreased with increase in clay content. Model equations generated 


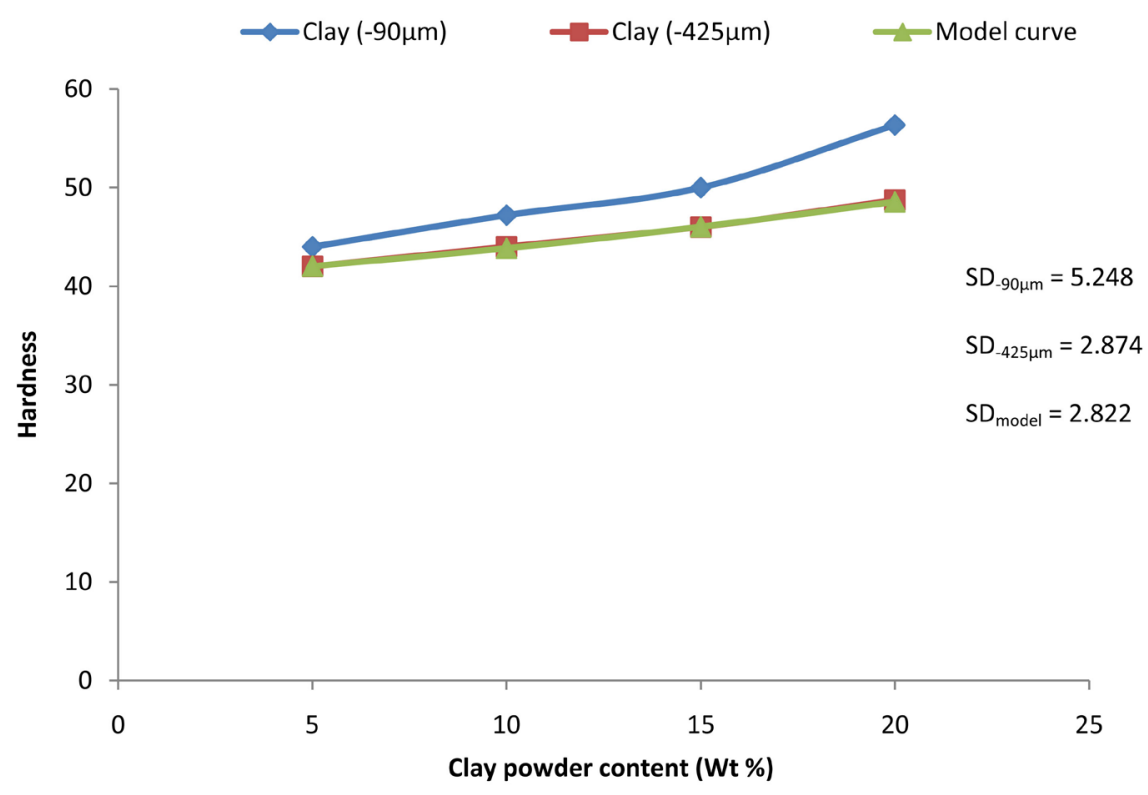

Figure 7. Variation of hardness with clay powder content for model and unmodel curves for the rLDPE composite at $-90 \mu \mathrm{m}$ and $-425 \mu \mathrm{m}$.

from the results showed that decrease in particle size enhanced most of the mechanical properties. These equations can also be useful for predicting the tested properties at predetermined clay powder contents. Standard deviations obtained for the various mechanical properties show that the model, in most cases had the lowest degree of scatter (dispersion) than those of $-90 \mu \mathrm{m}$ and $-425 \mu \mathrm{m}$. It is therefore recommended that these models be used to predict outcomes of clay filled recycled low-density polyethylene composite for laboratory and industrial production of the composite.

\section{Conflicts of Interest}

The authors declare no conflicts of interest regarding the publication of this paper.

\section{References}

[1] Ali, D.S.M., Alemzadeh, I., Reza, D.S.M. and Vosoughi, M. (2011) Studies on the Oxygen Barrier and Mechanical Properties of Low-Density Polyethylene/Organoclay Nanocomposite Films in the Presence of Ethylene Vinyl Acetate Copolymer as a New Type of Compatibilizer. Materials and Design, 32, 1806-1813. https://doi.org/10.1016/j.matdes.2010.12.028

[2] Beylergil, B., Tanoğlu, M. and Aktaş, E. (2017) Enhancement of Interlaminar Fracture Toughness of Carbon Fiber-Epoxy Composites Using Polyamide-6,6 Electrospun Nanofibers. Journal of Applied Polymer Science, 134, 45244. https://doi.org/10.1002/app.v134.35

[3] Ishida, H., Campbell, S. and Blackwell, J. (2000) General Approach to Nanocomposite Preparation. Chemistry of Materials, 12, 1260-1267. https://doi.org/10.1021/cm990479y

[4] Lama, C.K., Cheunga, H.Y., Laua, K.T., Zhoua, L.M., Hob, M.W. and Huib, D. 
(2005) Cluster Size Effect in Hardness of Nanoclay/Epoxy Composites. Composites. Part B, 36, 263-269. https://doi.org/10.1016/j.compositesb.2004.09.006

[5] Gopakumar, T.G., Lee, J.A., Kontopoulou, M. and Parent, J.S. (2002) Influence of Clay Exfoliation on the Physical Properties of Montmorillonite/Polyethylene Composites. Polymer, 43, 5483-5491. https://doi.org/10.1016/S0032-3861(02)00403-2

[6] Loganathan, R., Eunkyoung, S. and Behnam, P. (2011) Structure and Tensile Properties of Nanoclay-Polypropylene. Journal of Applied Polymer Science, 121, 410-419. https://doi.org/10.1002/app.33619

[7] Jo, C., Fu, J. and Naguib, H.E. (2006) Constitutive Modeling for Intercalated PMMA/Clay Nanocomposite Foams. Polymer Engineering \& Science, 46, 1787. https://doi.org/10.1002/pen.20656

[8] Shia, D., Hui, C.Y., Burnside, S.D. and Giannelis, E.P. (1998) An Interface Model for the Prediction of Young's Modulus of Layered Silicate-Elastomer Nanocomposites. Polymer Composite, 19, 608. https://doi.org/10.1002/pc.10134

[9] Arulmurugan, S. and Ventateshwaran, N. (2016) Vibration Analysis of Nanoclay Filled Natural Fibre Composites. Polymers and Polymer Composites, 24, 507-516. https://doi.org/10.1177/096739111602400709

[10] Fornes, T.D. and Paul, D.R. (2003) Modeling Properties of Nylon 6/Clay Nanocomposites Using Composite Theories. Polymer, 44, 4993.

https://doi.org/10.1016/S0032-3861(03)00471-3

[11] Onuegbu, G.C. and Madufor, I.C. (2012) Effect of Filler Loadings on the End-Use Properties of Maize Tassel Filled High Density Polyethylene. International Research Journal in Engineering, Science and Technology, 9, 2.

[12] Epaarachchi, J., Ku, H. and Gohel, K. (2010) A Simplified Empirical Model for Prediction of Mechanical Properties of Random Short Fiber/Vinylester Composites. Journal of Composite Materials, 44, 779-788. https://doi.org/10.1177/0021998309346383

[13] Raharjo, W.P., Soenoko, R., Purnowidodo, A. and Pham, M. (2018) Experimental and Micromechanical Modelling of Randomly Oriented Zalacca Fibre/Low-Density Polyethylene Composites Fabricated by Hot-Pressing Method. Cogent Engineering, 5, Article ID: 1518966. https://doi.org/10.1080/23311916.2018.1518966

[14] Atuanya, C.U., Aigbodion, C.S., Obiorah, S.O., Kchaou, M. and Elleuch, R. (2016) Emperical Models for Estimating the Mechanical and Morphological Properties of Recycled Low-Density Polyethylene/Snail Shell Bio-Composites. Journal of the Association of Arab Universities for Basic and Applied Sciences, 5, 45-52. https://doi.org/10.1016/j.jaubas.2015.01.001

[15] Onuegbu, G.C., Onyedika, G.O. and Ogwuegbu, M.O.C. (2019) Mechanical and Thermal Behaviour of Clay Filled Recycled Low Density Polyethylene. In: Ikhmayies, S., Li, J., Vieira, C., Margem (Deceased), J. and de Oliveira Braga, F., Eds., Green Materials Engineering, the Minerals, Metals \& Materials Series, Springer, Cham, 13-21. https://doi.org/10.1007/978-3-030-10383-5_2

[16] Uchechi, C.M., Madufor, I.C., Obasi, H.C. and Mark, U. (2019) Influence of Filer Loading on the Mechanical and Morphological Properties of Carbonized Coconut Shell Particles Reinforced Polypropylene Composite. Journal of Composite Materials, 54, 397-407. 